\title{
Pituitary adenomas in a cosmetics factory
}

\author{
D MIRABELLI, ${ }^{1}$ ENRICA CICCARELLI, ${ }^{2}$ F MERLETTI ${ }^{1}$ \\ From the Cattedra di Epidemiologia dei Tumori Umani ${ }^{1}$ and Dipartimento di Biomedicina, ${ }^{2}$ Universita di \\ Torino, 10126 Torino, Italy
}

We report three cases of acromegalic patients with growth hormone (GH) secreting pituitary adenomas (plasma GH values ranging from 100 to $185 \mathrm{ng} / \mathrm{ml}$ ), diagnosed at the endocrinological unit of the University of Torino, who worked in a cosmetics factory in northern Italy. In all patients the diagnosis was confirmed after surgery by histological, immunocytochemical, and ultrastructural analysis.

The factory has been operating since 1958 and comprises a base chemicals and intermediates warehouse, departments for compounding, packaging, and shipping finished products, and an analytical laboratory. The factory produces cosmetics such as creams, perfumes, colours, powders, make up creams, soaps, shampoos, lotions, lacquers, permanent wave lotions, hair dyes, bleaches, and nail varnishes.

In the compounding department base chemicals and intermediates are mixed; the finished products are piped into the automatic packaging lines in the packaging department, where filling into the appropriate container is performed, followed by capping, labelling, bag closing, box forming, etc. In the lacquer packaging lines propellents are added into the pressurised aerosol containers by injecting them through the cap valve. In the past hand packaging was frequent. Maintenance is performed by a maintenance staff and also by workers of the different departments.

At present the factory employs 387 subjects (clerks: 76 men, 71 women; blue collar workers and technical staff members: 110 men, 130 women) but a larger workforce was employed in the past-for instance, in 1970 there were 890 employees $(73,99 ; 236,482$ respectively. Allowing for a $10 \%$ turnover of the workforce a year, it can be estimated that the personyears of observation cumulated between 1958 and 1985 are $28000(2450,3250 ; 7500,14800$ respectively). Since we do not know the number of employees between 1958 and 1969, we assumed that the workforce was that of 1970 over the whole period, although we know that it had slowly increased from an initial 100 employees in 1958. The figure of 28000 person-years is likely, therefore, to be an overestimate.

We have no age specific data but, due to the young age at employment of subjects, most of the person-

Accepted 2 February 1987 years probably cumulated in the age groups under 60 -that is, the ages in which the highest incidence of all pituitary adenomas occurs. ${ }^{1}$

We have no proper incidence data on pituitary adenomas in the province where the factory is located for comparison. Nevertheless, data are available for the province of Varese, an industrialised area in northern Italy served by a tumour registry. For 1978-81 annual incidence rates in ages $30-59$ of all pituitary adenomas, of which $\mathrm{GH}$ secreting adenomas are a subset, were $2 \cdot 2 / 100000$ for men and $3 \cdot 1 / 100000$ for women ${ }^{2}$ (F Berrino, personal communication). These rates are within the range available for areas of different countries. ${ }^{1}$ Changes in the incidence of all pituitary adenomas are not expected to have occurred since $1958 .^{3}$

The expected figures for all pituitary adenomas in our cohort are 0.22 for men and 0.56 for women. Our endocrinological unit is not a reference centre for all pituitary adenomas in the area where the factory is located so that we cannot exclude that other cases may have occurred.

The three cases are: (1) A male blue collar worker was diagnosed in 1980 at age 55 . He had worked in the department of shipping finished products for 19 months in 1963-4 and for 30 further months between 1969 and 1972. At intervals he had also worked as a maintenance staff member in the packaging department. (2) A female blue collar worker diagnosed in 1981 at age 35 had worked in the packaging department for 19 years. (3) A male blue collar worker diagnosed in 1985 at age 27 had worked for 10 years as a mechanic in the maintenance staff in the packaging department.

We are not aware of case reports of pituitary adenomas in industrial settings and to our knowledge none of the substances used in the factory has been linked with pituitary adenomas either in animals or in man. We would be interested to receive information on similar unpublished observations.

\section{References}

1 Gold EB. Epidemiology of pituitary adenomas. Epidemiologic Reviews 1981;3:163-83.

2 Berrino F, Crosignani P, Gatta G, Macaluso M, Pisani P, Vigano C. Incidenza dei tumori e cause di morte in Lombardia. Regione Lombardia, Editore, Milano 1985.

3 Robinson B, Beral V, Ashley JSA. Incidence of pituitary adenomas in women. Lancet 1979;ii:630. 